\title{
Áreas inundáveis - Um desafio para Limnologia
}

Woifgang Johannes Junk (*)

\begin{abstract}
Resumo
No decorrer de estudos limnológicos nas áreas inundáveis (várzea) do Médio Amazonas, encontraramse dificuldades na aplicação da terminologia, dos conceitos e da metodologia desenvolvidas para os sistemas c!ássicos de água parada e água corrente. As pronunciadas oscilaçōes periódicas do nivel de água, em combinação com mudançás entre a fase aquática e a fase terrestre em grande escala, provocam condiçōes, que não correspondem nem a lagos e rios nem a pântanos e águas temporárias. Uma revisāo da literatura limnologica e ecológica mostra uma falta notável de trajaIhos que tratem da interrelação entre o meio ambiente aquático e terrestre, especialmente em relação às mucanças entre a fase aquática e a fase terrestre, que sẫo características para áreas inundáveis. Existem várias razōes para esta falta de estudos, entre outros દ. grande complexidade das condiçōes ecológicas nas áreas inundáveis, e uma certa interferência entre lim. nologia e ecologia terrestre, provocando um descuico por parte de ambas as ciências. As condições ecologicas das áreas inundáveis são descritas usando-se a várzea do rio Amazonas como exemplo. O impacto da mudança entre a fase aquática e a fase terrestre para a flora, fauna e o balanço de nutrientes é discutiao. Acentua-se o fato de que as áreas inundáveis mostram diferenças fundamentais relativamente aos sistemas clássicos de rio e lago, propondo-se tratá-los como ecossistemas especificos.
\end{abstract}

\section{INTRODUÇão}

A Limnologia não pode mais ser considerada como uma ciência muito jovem pelo fato de o seu início datar do fim do século passado. Os trabalhos clássicos de Forbes (1887) e Forel (1892 - 1901) vão da biologia dos organismos a considerações ecológicas, as quais mais tarde se manifestaram no conceito dos tipos de lagos de Naumann (1921, 1931 e 1932) e Thienemann (1921 1925, 1932 e 1933).

Desde essa época, a Limnologia se desenvolveu muito rapidamente abrindo novas áreas de trabalho, tais como, a paleolimnologia, a limnobacteriologia e a área complexa da limno- logia aplicada, abrangendo atualmente as águas naturais, como a observação de efeitos antrópicos sobre o meio ambiente aquático e a investigação da própria água de esgotos. Considerando este desenvolvimento impressionante, era de supor-se que a Limnologia atual tivesse em geral delimitada a sua área de pesquisa. Porém, uma análise mais minuciosa indica um desequilíbrio pronunciado em relação ao estudo dos fenômenos que cabem na área da Limnologia, como ciência abrangente das águas doces.

Este desequilibrio tem várias razões, duas das quais são de interesse específico neste contexto. Como foi observado por Thienemann (1932:205):

...o desenvolvimento de problemas cientificos depende da situação geográfica. O conceito dos tipos de lagos foi desenvolvido nas áreas temperadas do hemisfério norte e baseado até agora substancialmente nas condições da Europa do Norte e Europa Centrai.

Esta afirmação, na época atual, de certo modo é válida para toda a Limnologia. Os centros de desenvolvimento da Limnologia originaram-se nas áreas temperadas da Europa e da América do Norte e ficaram lá até hoje. Em conseqüência disso, existe um grande desequilíbrio de informações em relação às águas destas regiões em comparação com às águas tropicais. Os modelos elaborados nas regiōes temperadas, freqüentemente, estão sendo generalizados e aplicados no mundo inteiro. Em geral, os manuais de Limnologia tratam os fenômenos tropicais tão pouco que se poderia, de uma maneira exagerada, definir a Limnologia como a ciência das águas temperadas.

Além do desequilíbrio provocado pela situação geográfica dos centros de desenvolvimento da Limnologia, pode também verificar-se um desequilibrio no tratamento dos assuntos

\footnotetext{
$\left(^{\bullet}\right.$ ) - Instituto Nacional de Pesquisas da Amazônia, Manaus e Max-Planck Institut fur Limnologie, Abt. Tropenökologie, Plön, Alemanha.
} 
científicos. Isso ocorre, pelo menos temporariamente, em qualquer área científica e pode ser atribuido ao fato de que certos problemas são de interesse específico, sendo por isso estudados preferencialmente. Além disso, os objetos de estudo podem ser tão nítidos, que por causa disso concentram sobre si o interesse dos cientistas.

Isso, a nosso ver aconteceu na Limnologia, com relação aos lagos. Os primeiros trabaIhos limnológicos (Forbes, 1887; Forel, 1892 - 1901) tratam de lagos. Birge \& Juday (1911) investigaram o balanço de oxigênio nos lagos de Wisconsin, e Thienemann e Naumann elaboraram entre 1915 e 1935 o conceito dos tipos de lagos. Com toda razão, o termo "Limnologia" antigamente foi traduzido como "Ciência dos lagos", apesar de na sua proposta para a fundação da Sociedade Internacional de Limnologia Teórica e Aplicada, Naumann \& Thienemann (1922) definirem Limnologia como ciência da água doce em geral, incluindo os fenômenos ligados a ela, dando-lhe desta forma uma importância mais abrangente. Apesar disso, o lago ficou sendo o objeto de estudo principal dos limnólogos, e o primeiro conceitc fundamental da Limnologia.

Ule (1925) classificou, baseado em pontos de vista geográficos, as águas correntes (rios e igarapés). Nos anos seguintes, elas foram incluídas nos estudos limnológicos mas, até agora, não chegaram à mesma importância dos lagos. Isso é refletido no número menor de trabalhos aos rios e igarapés, porém estes representam os objetos para o segundo conceito fundamental que descreve as águas correntes em comparação com as águas paradas. Além disso, as águas naturais foram classificadas em águas superficiais e subterrâneas, e em águas permanentes e temporárias.

Porém, temos que perguntar se essa classiŕicação é suficiente para abranger a grande variedade de manifestações de águas naturais. Ao nosso ver, esse não é o caso. Gostaríamos de demonstrar isso nos capítulos seguintes comparando os conceitos já bem estabeleciaos de água parada, (lago) e água corrente (rio) com áreas inundáveis em geral, e, especificamente, com a área de inundação tropical do médio Amazonas, a "várzea".(')

CARACTERIZAÇão dos SISTEMAS CLÁsSicos DE LAGO E RIO (ÁGUA PARAdA E ÁGUA CORRENTE)

Com poucas exceções (por ex. Schwoer. bel, 1971), em manuais limnológicos não se encontra uma definição dos termos lago e rio (Ruttner, 1952; Hutchinson, 1957; Wetzel, 1975 etc.). Conforme Schwoerbel (1971), lagos săo grandes coleções de águas paradias sem iigação direta com o mar, distribuídas como ilhas na terra. Eles contêm geralmente água doce, pobre em eletrólitos, com exceção de lagos salobres, que ocorrem em climas áridos. Do ponto de vista geológico, eles são, com poucas exceções, relativamente jovens, de pouca duração, porque eles têm caráter acumulativo (sistemas mais ou menos fechados).

A classificação dos lagos é feita através da sua gênese e/ou através do seu nível trófico. Hutchinson (1957) difere 11 tipos principais com 76 subtipos, e Wetzel (1975) 9 tipos principais. Schwoerbel (1971) cita 3 tipos principais como de importância especial. A classificação dos lagos, conforme o seu nivel trófico, baseando-se na tipologia do Thienemann e Ruttner, é de maior interesse para os limnólogos e foi várias vezes discutida e aperfeiçoada nos últimos anos (Elster, 1956, 1958 e 1962; Brundin, 1956).

Decisivo para o estudo dos lagos é o fato de que eles são considerados como formações com limites bem definidos, sendo a superfície e a profundidade consideradas como relativamente constantes durante o periodo do esturio. No entanto, quase todas as águas naturais, lagos e rios, estão submetidos a flutuações de nivel. que em dependência do clima e do relevo influenciam áreas de tamanho diferente durante épocas de duração variável. Nas regiões temperadas, estas mudanças de nível de água são provocadas normalmente pelo degelo e pela relação entre precipitação e evaporação durante o ciclo do ano. Porém, geralmente,

(1) - Considerando a complexidade do problema, muitos aspectos podem ser tratados só superficialmente. Por isso, foram citados muitos manuais, nos quais o leitor pode encontrar informaçōes mais minuciosas sobre a literatura mais especifica. 
elas são consideradas na Limnologia como oscilaçōes insignificantes ao redor de um nivel "normal", especialmente porque elas raramente ultrapassam em lagos clássicos uma altura de $1-2 \mathrm{~m}$, tendo por isso relativamente pouca influência na área total e na profundidade do lago $\mathrm{De}$ acordo com Hutchinson (1957: 165):

The maximum idepth will vary slightly with variations in water level, and ideally it should bo referreci to some independent datum level.

Este acordo implícito demonstra-se claramente na terminologia limnológica. Todos parâmetros morfométricos tais como comprimento, largura, profundidade, perímetro, área, volume $e$ outros estâo sendo considerados como constante, mesmo sendo submetidos às oscilaçōes. A partir destes parâmetros, definem-se outros termos limnoiógicos tais como pelagial. bental, litoral, profundal, os quais indicam biótopos característicos. A sua extensāo depende da morfologia da bacia do lago (profundidace) e, no caso do litoral e profundal, adicionalmente da espessura da camada eufótica. Neste contexto, têm que ser citados, também, os termos "alóctone e autóctone". Estas definiçōes basciam-se em uma separação precisa entre a zona terrestre e a zona aquática.

Aguas correntes são definidas do ponto de vista hidrológico como uma "calha" ("Gerinne"), na qual é transportada a descarga de água superficial (sistemas abertos) (Schwoerbel, 1971: 12). A sua classificação é muito mais difícil do que a classificação de lagos, porque a sua gênese não é um processo tão significativo. Característico para águas correntes é o fato, de que elas transportam substâncias com a sua energia cinética e as levam - em geral - ao mar. Além do transporte permanente de substâncias em solução, isso tem também como consequeência a deslocação de material insolúvel, que se realiza no curso superior, sobretudo sob a forma de erosão, e no curso inferior sobretudo sob a forma de sedimentação.

Segundo as modificações hidrográficas que ocorrem ao longo do rio, e que atingem espe. cialmente a velocidade da correnteza, a estrutura do fundo do leito e, em particular nas zonas temperadas, o balanço de temperatura, os rios são diferenciados em região da fonte (Eucrenon e Hipocrenon) região superior (Ritron) e regiăo inferior (Potamon). As duas últimas regiōes podem ser subdivididas, acrescentando-se os prefixos Epi- Meta- e Hipo- (lllies, 1961). Estudos de vários autores (Müller, 1951, Illies, 1953, 1955 e 1961; Illies \& Botosaneanu, 1963, e outros) mostram, que os diferentes trechos correspondem a diferentes biocenoses. Especialmente a ictiofauna está sendo usada para a sua caracterização (Müller, 1951 e 1955) Rzóska (1978) discute a existência de potamoplâncton em rios de diferentes comprimentos e usa o termo "ontogenia" em relação ao desenvoivimento desde o igarapé até o rio. $\left[{ }^{[}\right]$

iMudanças de nivel de água ocorrem em águas correntes com maior treqüência e em maıor escala. Hynes (1972) chama a atenção para o tato de que a indicação da descarga media de rios, em primeiro lugar, é de interesse ustaustıco, nao alcançando ela este valor. uurance a maır parte do ano $(<75 \%)$. Baseanco-se na iteratura existente, ele discute a inruencia da cheia e da seca sobre a tauna e riora tluvial propriamente dita, excluindo porem as áreas alagadas. Na descrição comparauiva dos rios Nilo, Zaire e Amazonas, Rzóska (1978) também focaliza principalmente o rio "senso strito", quer dizer, a área da água corrente propriamente dita. Ele considera as varzeas enormes desses rios como parte do sistema, se bem que elas nāo mostrem as caracteristicas de rios tais como correnteza unidirecional e transporte de água e substâncias.

\section{RELAÇÃO ENTRE O MEIO AMBIENTE AQUÁtICO} E O MEIO AMBIENTE TERRESTRE

Desde o início, os limnólogos estudaram a influência do meio ambiente terrestre sobre os sistemas aquáticos, sublinhando a importância desta relação para a Limnologia $\left({ }^{3}\right)$. Nas

(2) - Em regiōes com alta taxa de poluição, está sendo usada também a classificação através do sistema dos sapróbios (Caspers \& Schultz, 1960; Elster, 1962 e 1966, e outros).

(3) - A palavra de Thienemann: "vamos para a terra": (através Illies \& Schwabe, 1959; 395).

Áreas... 
últimas décadas, aumentou o interesse nesta problemática (Hasler, 1974). Principalmente a eutroficação crescente da água, provocada pelo aumento de fertilizantes usados na agropecuária e pela destruição da vegetação natural das margens dos lagos provocou estudos adicionais.

Com a intensificação da piscicultura, especialmente na Europa Central e Oriental, aumentou o número de estudos sobre o ciclo de nutrientes e a biocenose em tanques de piscicultura periodicamente secos. As grandes oscileções artificiais em represas, exigiram estudos a respeito de sua influência sobre a qualidade da água e a biocenose. Aumentou também o número dos trabalhos limnológicos realizados em regiões tropicais, especialmente porque os problemas surgidos em combinação com projetos de desenvolvimento (represas hidrelétricas, plantio de arroz em grande escala (Heckman, 1979), pesca (Welcomme, 1979)) exigiam estudos pormenorizados em áreas inundáveis. Para a região amazônica, deveriam ser mencionadas especialmente os trabalhos de Sioli $(1954,1964,1968,1973,1975$ e outros) que discutem a relação entre os rios e o meio ambiente terrestre. Gessner (1955) descreve as conseqüências morfológicas para as hidrófitas advindas com a mudança do meio ambiente aquático para o meio ambiente terrestre e focaliza a necessidade de estudos minudentes em áreas de várzea $\mathrm{e}$ igapó. $\left({ }^{4}\right)$

Estudos fitossociológicos dão informações sobre comunidades de plantas em áreas de inundação, principalmente em regiões temperadas (Hejny, 1960; Dister, 1980).

No entanto, a grande maioria dos estudos mencionados tratam de aspectos específicos do problema geral e principalmente da influência do meio ambiente terrestre sobre o meio ambiente aquático. O número de estudos, que tratam da influência do meio ambiente aquático sobre o meio ambiente terrestre, que em áreas inundáveis é da mesma importância, é muito limitado, e o passo de considerar esta área de transição como uma unidade ecológica e de estudá-la de uma maneira abrangente, tem que ser ainda feito na Limnoiogia.

Estudos abrangentes sobre áreas de inundação são escassos e podemos oferecer vários argutnentos para isso. Primeiro, nas regiões altamente industrializadas, tais como Europa e A.mérica do Norte, as grandes áreas de inundação foram modificadas ou mesmo destruídas, há séculos pelas construções hidráulicas tais como, diques, canais, retificações do leito, etc., porque as inundações freqüentes prejudicaram o aproveitamento tradicional das áreas atingidas. Longos trechos do leito do rio Reno, por ex... foram retificados já no século passado. É possível prever que nos próximos anos, face às amplas construções de diques no delta do Danúbio, a última grande área de inundação da Europa será profundamente modificada. Por causa destas modificações antrópicas, os limnólogos tiveram somente possibilidades ou necessidades limitadas de estudar áreas de inundação em regiões temperadas.

Ao contrário de regiões tropicais, nas quais os processos abióticos e bióticos realizam-se 0 ano inteiro, com alta velocidade, dada a temperatura elevada, nas regiões temperadas há, durante o inverno, um período de repouso provocado pela temperatura baixa e pela insolação reduzida. Este período de repouso freqüentemente influência a fauna e flora durante a época da enchente, muitas vezes provocada pelo degelo.

Além disso, a existência de áreas inundáveis depende dos rios ou lagos, dos quais eles recebem água e para as quais uma parte desta água volta. Por causa disso elas são tradicionalmente consideradas como parte destes sistemas ou, para exagerar, como apêndices periodicamente desenvolvidos de baixa importância e de caráter inespecífico. Na realidade, clas têm influência importantíssima sobre os rios e lagos em conexão.

A subdivisão do litoral em epi-supra- e eulitoral indica a importância que os limnólogos dão à área de interferência entre o meio ambiente aquático e o meio ambiente terrestre. Porém, estes termos baseiam-se, em geral, em

(4) - "Levanta-se a pergunta: Quais săo as adaptações que permitem às plantas da "várzea" e do "igapó" sobreviver o período submerso do ciclo de vida. O estudo minucioso destes problemas é um desafio interessante para os ecólogos. 
idéias espaciais fixas, não abrangendo a dinâmica ligada às mudanças periódicas e em grande escala entre meio ambiente terrestre e meio ambiente aquático, provocadas pelas grandes oscileções de nível de água. Os termos estr̄o sondo usados da mesma maneira pelos ecólogos terrestres (Tischler, 1955; Odum 1959; Schwerditfeger, 1975); o último autor citado indice a necessidade de uma análise mais abrangente do problema (Ibid.: 71-72) .

Adicionalmente a estes argumentos, aparentemente tanto os ecólogos terrestres, quanto os limnólogos, evitam o problema porque áreas inundáveis pertencem, em certa época, ao meio ambiente aquático e mudam depois para ambiente terrestre, reduzindo assim o interesse dos cientistas, que não querem envolver-se com problemas que em parte atingem áreas fora da sua atuação normal. Apesar de várias tentativas de tratar a relação entre o meio ambiente aquático e meio ambiente terrestre de uma maneira abrangente - Schwabe \& Klinge (1960) usam o termo "Grenzunschärfe" - pode ser comprovado de forma geral que, até hoje em dia, existe na limnologia uma tendência de delimitar claramente o meio ambiente aquático e o meio ambiente terrestre e de tratar ambos como unidades separadas.

Nos últimos anos, o termo "wetland" está sendo usado para denominar áreas de transição entre o meio ambiente aquático e o meio ambiente terrestre. Gosselink \& Turner (1978) focalizam a importância da hidrologia em "wetlandis". Porém, o termo está sendo usado na literatura tanto para os ecossistemas com grandes oscilações de nível de água, como para os com condições hidrológicas estáveis. Neste contexto, surge a pergunta quanto ao valor dos numerosos estudos sobre pântanos para a análise da interação do meio aquático e o meio terrestre. Sem dúvida alguma, estes ecossistemas mostram características transitórias. Porém, temos que considerar que estes ecossistemas, tanto como o litoral de lagos, representam apenas alguns exemplos do grande número das diferentes possibilidades de transição dentre o meio terrestre e meio aquático.
Pântanos possuem, como a maioria dos lagos clássicos, uma certa constância espacial e temporai em relação à sua estrutura e estratificaçāo. Esta constância na relaçāo entre o meio aquático e o meio terrestre não existe em áreas alagáveis. A classificação dos corpos de água como perenes e temporários também não é completamente adequada para áreas inundáveis. tmbora a época seca provoque condiçōes que em certos pontos correspondem às condiçoes de águas temporárias, a conexão de áreas ınundáveis com águas perenes influencia o seu balanço de nutrientes e a sua biocenose de uma maneira fundamental, separando-Ihes claramente de águas temporárias. Áreas inundáveis marítimas como os manguezais já demonstraram ser ecossistemas específicos, com caracteristicas bem expressivas.

Pode argumentar-se que, na Limnologia, sempre vai haver problemas de interesse para estudos, porém a sua importância para a Limnologia em geral é secundária. Isso não consta para áreas inundáveis. Além dos inúmeros problemas científicos a elas relativos, elas coorem grandes áreas na terra. Schwoerbel (1971) indica o total da área coberta por lagos chegando a cerca de $2.5 \times 10^{6} \mathrm{Km}^{2}$. Uma estimativa aproximada de áreas inundáveis chega a este valor ou até mais.

CARACTERIZAÇÃo DE ÁREAS INUNDÁVEIS BASEADA NA VÁRZEA DO MÉDIO AMAZONAS

\section{ORIGEM DA VÁRZEA}

A várzea do Amazonas extende-se dos Andes até o Oceano Atlântico com uma largura de $20-100 \mathrm{~km}$. Sua área foi calculada por Castro Soares (1956) em $64.000 \mathrm{~km}^{2}$. A fotografia aérea mostra um sistema complexo de canais, lagos de várzea $\left({ }^{5}\right)$, ilhas e diques marginais (Fig. 1a, 1b, 2) .

A formação desta região pode ser explicada da seguinte maneira: 75.000 anos atrás, o nivel do mar esteve cerca de $100 \mathrm{~m}$ abaixo do nivel atual durante um período de cerca de 50.000 anos (Fairbridge, 1961). Em conse-

(5) - De acordo com a tipologia de Hutchinson (1957), estes lagos correspondem ao grupo de "lagos de áreas inundáveis maduras" (tipo 55-59, p. 162). Todavia, muitos destes lagos têm que ser considerados como vales inundados (Sioli, 1964). Este tipo não está mencionado na classificação de Hutchinson. 


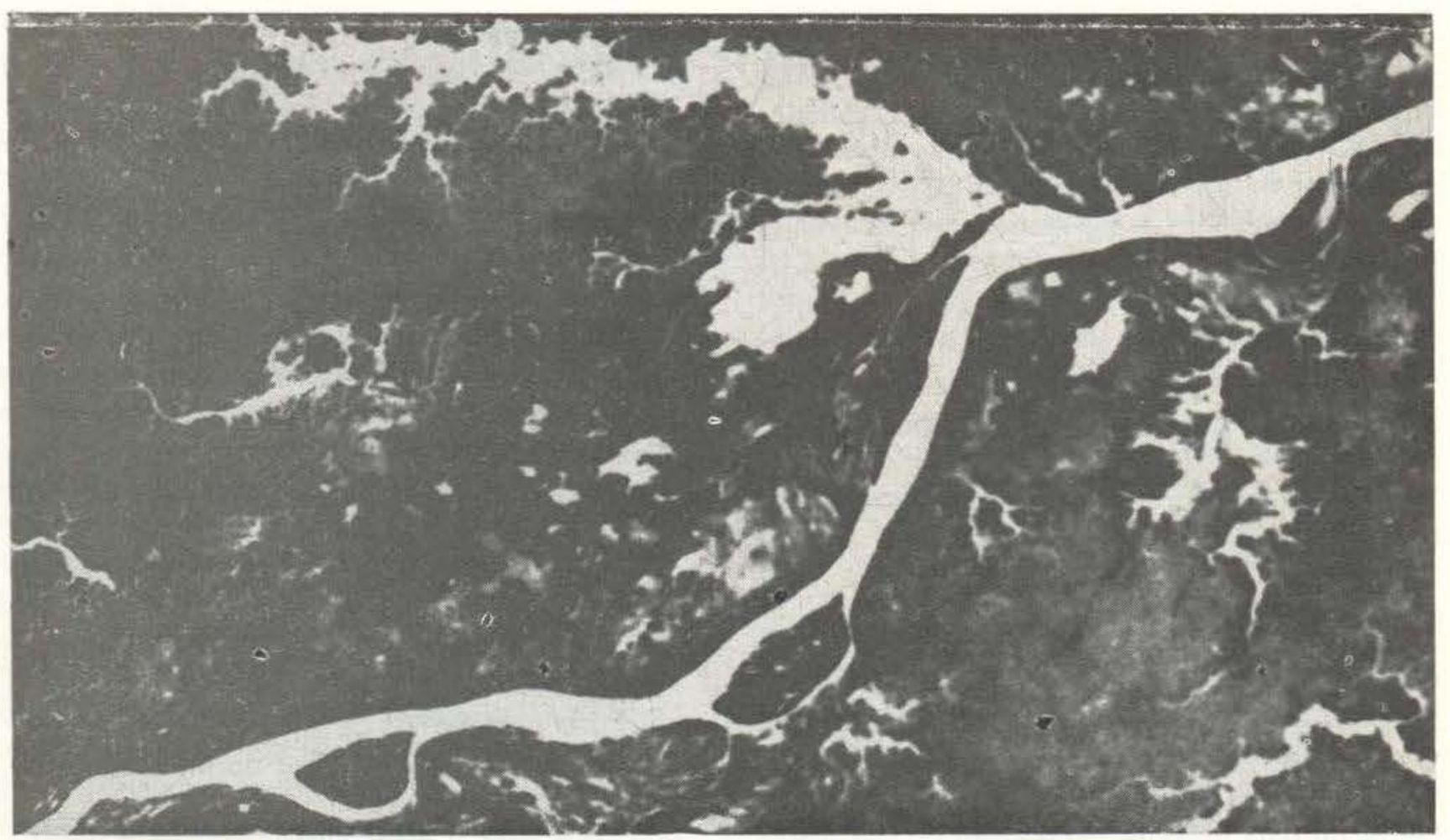

$\alpha$

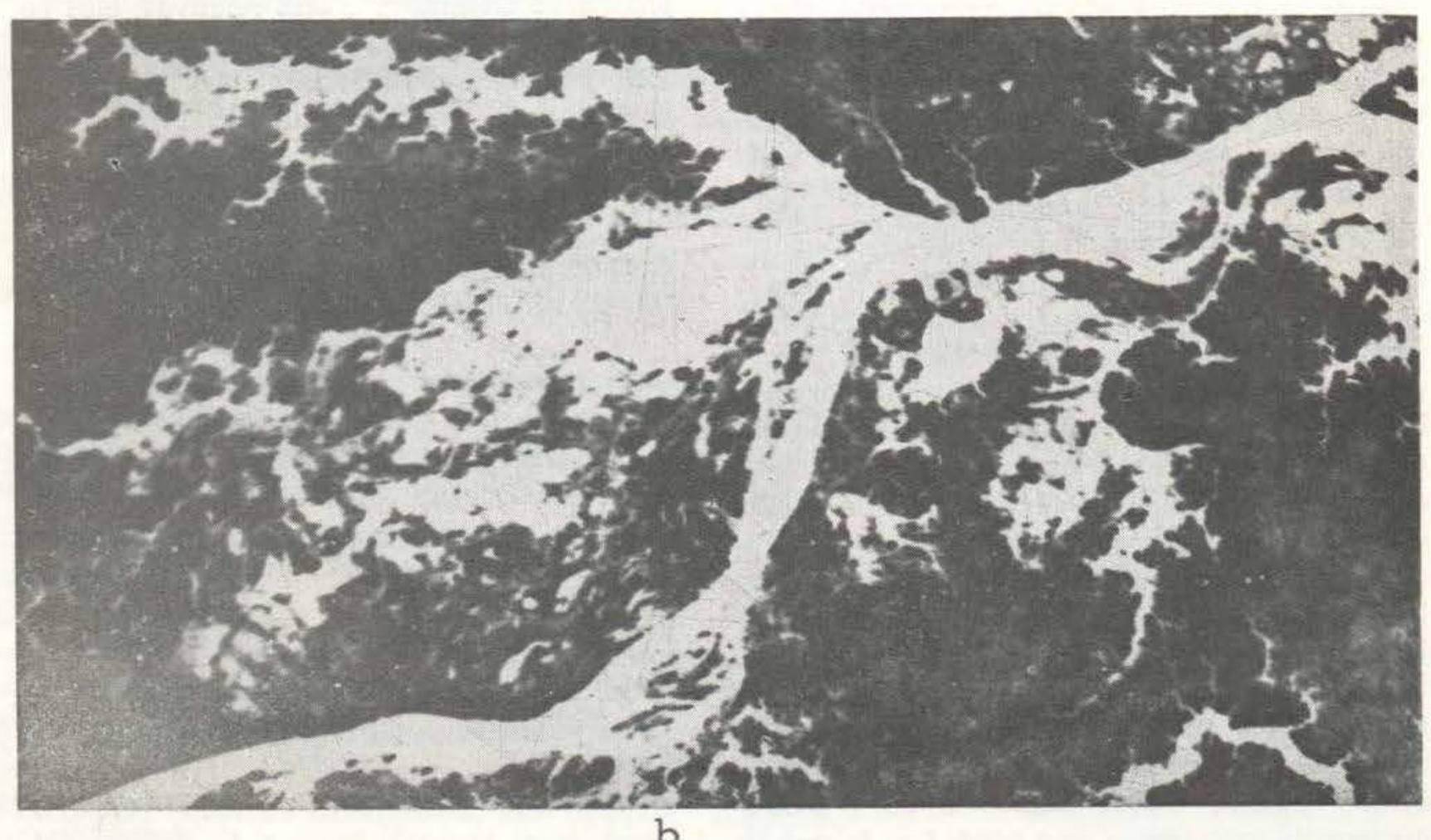

Fig. 1 - Fotografia aérea da várzea do Médio Amazonas, próximo de Manaus: a) Durante água baixa (09.12.76); b) Durante água alta $(31.07 .77)$. As fotos não mostram uma situação extrema entre estes dois periodos porque a diferença do nivel de água somente chegou a $8.62 \mathrm{~m}$, sendo o valor médio cerca de $10 \mathrm{~m}$ e o valor extremo cerca de $15 \mathrm{~m}$. Além disso, a floresta inundada e as macrófitas aquáticas indicam na cheia terra em lugares nos quais, em realidade, ocorre água. (Foto do CNPq, INPE-Landsat - São Paulo). 


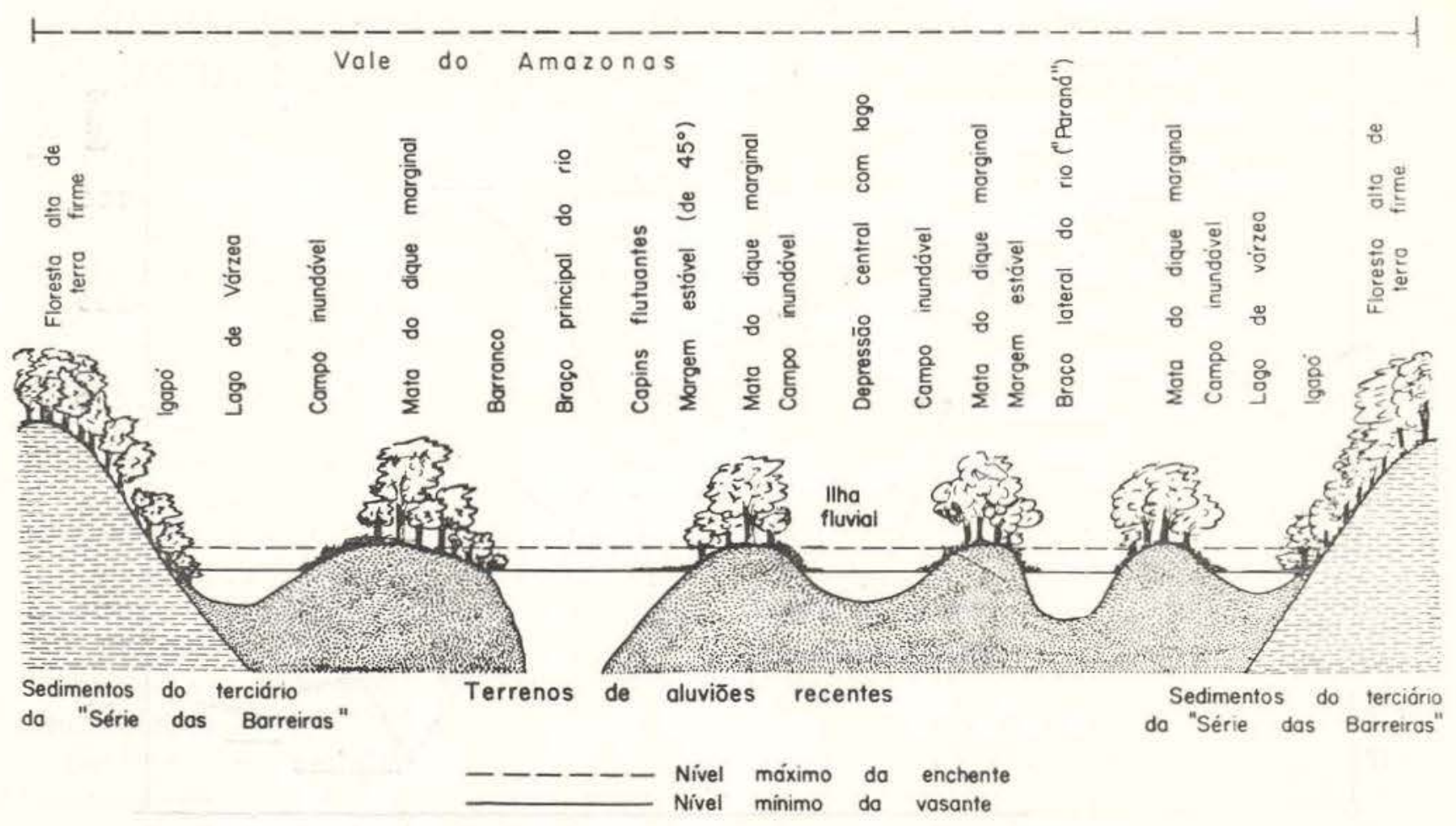

Fig. 2 - Corte esquemático pelo vale do Amazonas, com as diferenças de altura exageradas (Conforme Sioli, 1964).

qüência da baixada do nível do mar, o rio Amazonas e seus tributários formaram largos e fundios vales. A subseaüente subida do nível do mar, até o seu nível atual provocou um represamento dos rios nos seus próprios vales. Considerando o fato de que mais de 1.000 .000 $\mathrm{km}^{2}$ da bacia amazônica estão situadas abaixo da isohipse de $100 \mathrm{~m}$, este represamento teve efeitos no vale do Amazonas até ao sopé dos Andes. Depcis, os rios começaram a encher os seus vales afogados com sedimentos recentes conforme sua carga sedimentária. No caso do Amazonas, que transporta grandes quantidades de sedimentos dos Andes e da zona Pré-Andina, este processo de sedimentação aparentemente já foi completado. Foi alcançado um novo equilíbrio que inclui amplos processos de sedimentação e erosão na própria várzea, que está sendo modificada permanentemente pela atividade do rio.

\section{CLIMA E HIDROLOGIA}

A precipitação na área da captação do rio Amazonas é de importância fundamental para a sua descarga. A precipitação total na bacia amazônica varia entre 1.800 e $3.000 \mathrm{~mm} /$ ano chegando em Manaus a cerca de $2.100 \mathrm{~mm} /$ ano. Nas encostas dos Andes, podem ser atcançados valores acima de $5.000 \mathrm{~mm} /$ ano. A precipitação não é distribuída igualmente durante o ano inteiro, provocando uma época seca e uma época chuvosa bem distinta (Fig 3). Esta periodicidade de precipitação provoca pronunciadas flutuações de nível de água, que alcançam perto de Manaus um valor médio de $10 \mathrm{~m}$, e, em caso extremo, de $15 \mathrm{~m}$ (Fig. 3). Ao nível máximo toda a várzea é inundada, enquanto ao nível mais baixo a maior parte é seca. (Fig 1a, e 1b).

Ao contrário de lagos clássicos, lagos de várzea são submetidos a grandes oscilações de área e profundidade durante o ano. 0 lago típico de várzea, perto de Manaus, com uma profunciidade máxima de cerca de $13 \mathrm{~m}$ e uma área de cerca de $6 \mathrm{~km}^{2}$, durante uma enchente normal, reduz, durante a seca, sua área para aprox. $2 \mathrm{~km}^{2} \mathrm{com}$ uma profundidade máxima de $2 \mathrm{~m}$. O mesmo lago pode secar ainda mais em 


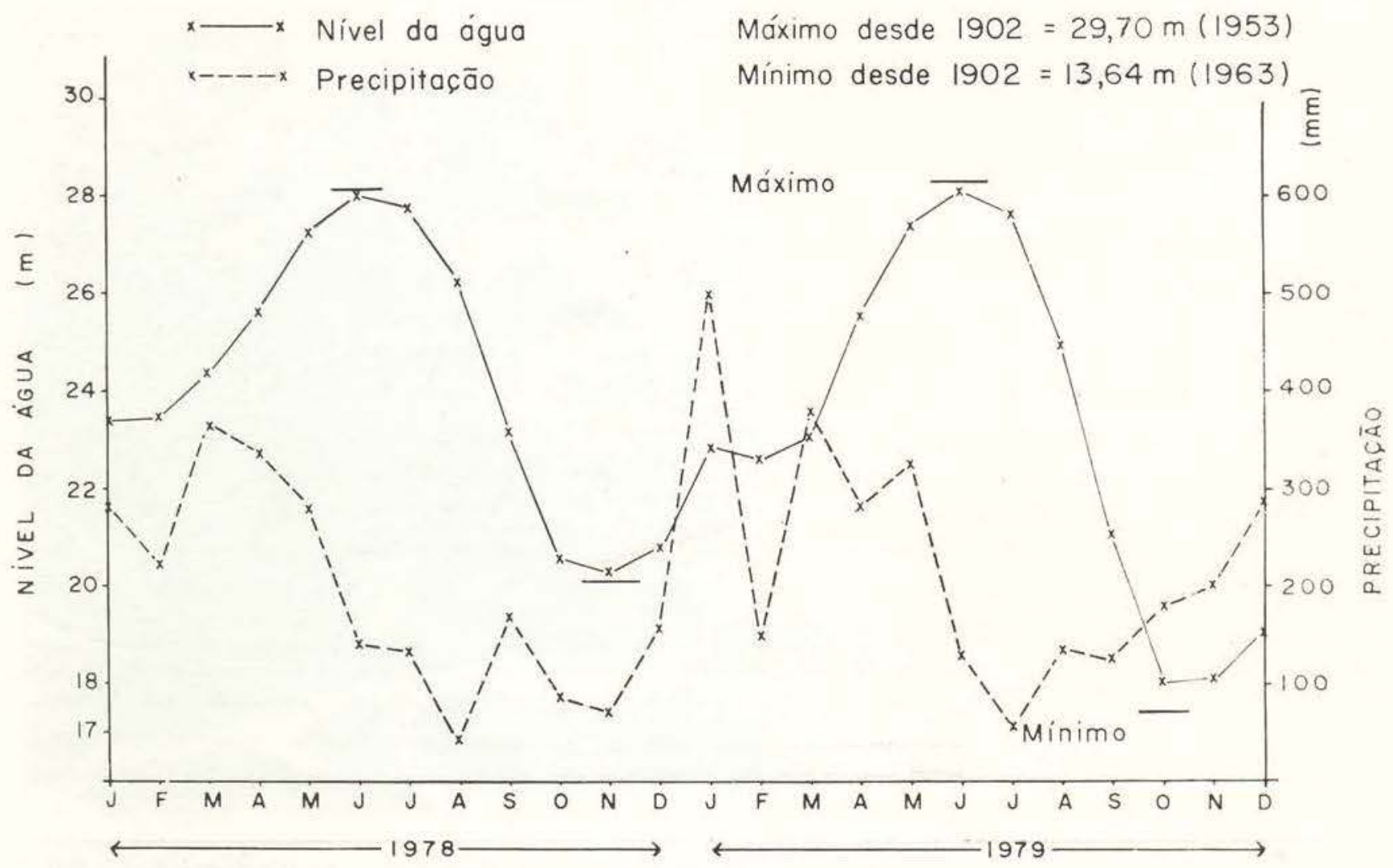

Fig. 3 - Flutuaçōes de nivel de água do Solimōes e precipitação perto de Manaus (Dados do nível de água: Capitana dos Portos, Manaus; dados de precipitação: Maria de Nazaré Góes Ribeiro, INPA, Manaus).

anos com nível do rio extremamente baixo, enquanto que durante uma cheia bem pronunciada a sua área não pode ser determinada porque ele está em contato com outros lagos.

A oscilação do nível do rio influencia os lagos de várzea de diferentes maneiras, dependendo da conexão entre o rio e o lago. Esta conexão pode ser temporária ou permanente, conforme a morfologia do lago, a sua posição e o seu tamanho. Pequenos lagos podem secar completamente, enquanto que partes de lagos podem atuar em certas épocas como canais naturais, contendo água corrente ou água parada, dependendo do nível de água.

Estas drásticas mudanças no sistema aquático naturalmente complicam a aplicação da terminologia desenvolvida para lagos clássicos. Faz-se portarito necessário uma nova discussão desses conceltos e termos em relação às áreas inundáveis.
ESTRATIFICAÇÃo E CONDIÇÕES DE OXIGÊNIO NOS LAGOS DE VÁRZEA

Hutchinson \& Löffler (1956) classificaram lagos de acordo com o seu tipo de circulação, incluindo também uma discussão sobre lagos tropicais. De acordo com esta classificação, lagos de várzea têm que ser considerados como oligomícticos durante a cheia e polimícticos durante a água baixa. A circulação da água, durante a seca, não se realiza tanto por causa da temperatura mas por causa do vento. Durante este período, os lagos são rasos e normalmente túrbidos porque as camadas superiores dos sedimentos são levantadas, sendo eles, em parte, retransportados ao rio. Por causa disso, sedimentos não perturbados, comparáveis aos sedimentos de lagos clássicos. podem ser encontrados somente, às vezes, em lagos de várzea (Schmidt, 1973a). 
O gradiente de temperatura da água pode alcançar até $4{ }^{\circ} \mathrm{C}$ durante a cheia. Esta estratificação pode ser relativamente estável, principalmente em áreas protegidas contra o vento, por causa da grande diferença de densidade da água entre $26^{\circ} \mathrm{C}$ e $30^{\circ} \mathrm{C}$. Intimamente ligadas à estratificação térmica, estão as concentrações de oxigênio. O aumento da temperatura não somente diminui a solubilidade do oxigênio na água mas, aumenta, além disso, o consumo de oxigênio por causa de taxas de decomposição crescentes. Por isso muitos lagos tropicais freqüentemente têm baixas concentrações de oxigênio, logo abaixo da camada eufótica e o sulfeto de hidrogênio é comum nas zonas mais fundas. Em lagos de várzea, esta situação é ainda mais pronunciada porque durante a enchente grandes quantidades de matéria orgânica provenientes da vegetação terrestre inundada, estão à disposição dos processos de decomposição. Além disso, grandes quantidades de macrófitas aquáticas e a floresta inundada diminuem a insolação na superfície da água, reduzindo assim a produção de oxigênio pelo fitoplâncton (Schmidt, 1973a).

As constantes mudanças do nível de água provocam mudanças das correntezas no sistema aquático. Corpos de água que ficaram parados durante vários meses, podem circular completamente por causa de correntezas provocadas pela mudança de nível de água. Em conseqüência disso, pode diminuir drásticamente a concentração de oxigênio na coluna da água. Em geral, as condições de oxigênio nos lagos de várzea podem ser consideradas como precárias porém, durante a enchente, a entrada de água do rio Amazonas, rica em oxigênio, garante concentrações elevadas em áreas perto do rio e diretamente influenciadas por ele.

A fauna aquática desenvolveu várias adaptações para suportar as baixas concentrações de oxigênio. Reiss (1976) indica a migraçäo de larvas de Chironomideos entre o fundo do lago e as macrófitas flutuantes para evitar condições precárias de oxigênio com a subida da água. Muitas espécies de peixes possuem órgãos respiratórios adicionais. A bexiga natatória do pirarucu (Arapaima gigas) é modificada para servir como um tipo de pulmão. Respiração intestinal é muito comum entre os bagres, como no tamoatá (Callichthys callichtys) e no acarí bodó (Callichthys spp., Plecostomus ssp.) O muçum (Symbranchus marmoratus) possui modificações na cavidade branquial. Saint-Paul (com.pess.) realizando experimentos com o tambaqui (Colossoma macropomum) verificou que o peixe somente sobe para a superfície da água quando a concentração de oxigênio baixa para menos de $0,5 \mathrm{mg} / \mathrm{O}_{2} / 1$. Apesar desta resistência impressionante de muitas espécies contra baixas concentrações de oxigênio, pode ocorrer mortalidade de peixes em certas épocas. Durante maio e junho, friagens podem provocar uma mistura total da coluna da água durante $2-4$ dias, com redução drástica da concentração de oxigênio e o aparecimento de traços de $\mathrm{H}_{2} \mathrm{~S}$ em toda a coluna de água (Santos, 1973). O mesmo pode acontecer durante a água baixa por causa do levantamento da lama pela atividade da pesca para explorar os estoques pesqueiros concentrados nos lagos rasos.

\section{ADAPTAÇÕES DE PLANTAS E ANIMAIS} Às FLUTUAÇõES DO NÍVEL DE ÁGUA

A mudança periódica entre a fase terrestre e a fase aquática é o fator mais importante para os organismos da várzea e de áreas inundáveis em geral. Muitos organismos são adaptados de várias maneiras para a vida, em ambas as fases. Normalmente, uma delas é desfavcrável ou até catastrófica para eles. Por isso, eles têm que recuperar, durante a fase favorável, as perdas que as populações sofreram durante a fase desfavorável. Além disso, eles têm que garantir a sobrevivência de uma parte da população durante a próxima fase desfavorável. O nosso conhecimento a respeito desses mecanismos, na região amazônica, é ainda muito limitado. Porém, podem verificarse várias tendências, que serão descritas em seguida.

\section{Macrófitas da várzea}

Durante a enchente, uma área crescente está à disposição de macrófitas aquáticas. Porém, partículas inorgânicas em suspensão e material húmico colorido em solução, provocam condições de luz desfavoráveis e a zona eufó- 
tica normalmente abrange menos de $4 \mathrm{~m}$. Normaimente, não existem plantas submersas enraizadas no fundo dos lagos porque pela subida das águas, as condições de luz são rapidamente pioradas nas áreas que poderiam ser colonizadas. Em conseqüência disso, um modo de vida flutuante é uma adaptação muito comum às oscilações do nível de água (Junk, 1970). Utricularia foliosa e Ceratophyllum demersum representam macrófitas flutuantes submersas, porém a grande maioria das espécies flutuantes são emersas tais como Eichhornia crassipes, Pistia stratiotes, Ceratopteris pteridoides, Salvinia auriculata, S, minima, Limnobium stoloniferum, Neptunia oleracea, Azolla sp., etc. Plantas enraizadas nos sedimentos crescem rapidamente para garantir a presença de suas folhas na superfície da água (Victoria amazonica) ou acima dela (Oryza perennis).

Todas as espécies mostram um rápido crescimento e alta taxa de reprodução. A reprodução vegetativa garante a coionização rápida das crescentes áreas que estão à disposição das plantas, por causa da subida da água. Este deserivolvimento é interrompido quando a água baixa, diminuindo as áreas aquáticas e provocando a mortalidade de até mais de $90 \%$ da vegetação aquática. As plantas sobrevivem à época seca em forma de sementes ou esporos e/ou pelo desenvolvimento de formas de crescimento terrestre. Muitas espécies possuem uma alta plasticidade morfológica e fisiológica que thes permite sobreviver em lugares úmidos e sombreados em forma modificada (Gessner, 1955). A tendência das modificações nessas espécies é deixá-las menores e mais rígidas, com menor conteúdo de água e redução de órgãos flutuadores ( $p$. ex. Neptunia oleracea, Ludwigia natans e Paspalum repens).

As áreas que secam são colonizadas rapidamente por vegetação terrestre, ou explicando mais precisamente, por vegetação que tem a sua época de crescimento na fase terrestre. Estas plantas desenvolvem-se através de sementes (p.ex. Cyperus ferax, C. odoratus, Eleusine indica, Paspalum spp.) ou de partes vegetais capazes de sobreviverem à época de inundação (Paspalum fasciculatum). Paspalum fasciculatum perde as folhas sob a água, mas a maicr parte dos caules sobrevive à inundação e começa a brotar logo depois de sair da água. Decisivo para o êxito de colonizar permanentemente estas áreas, é a capacidade das plantas de terminar o ciclo de reprodução durante a época seca, a produção de um número suficiente de sementes e a sobrevivência delas e/ou de partes vegetais durante a cheia. A dispersão das sementes é importante para possibilitar a colonização de áreas recém-formadas pelo rio. Ela depende do transporte pela água, pelo vento e/ou animais.

As mesmas estratégias encontram-se em muitas árvores e arbustos que formam as características das matas inundáveis da várzea. As espécies que colonizam as áreas mais baixas como Salix humboldtiana, Eugenia inundata e Symmeria paniculata, necessitam de um período de $4-5$ meses por ano de seca para uma colonização eficaz. Elas podem também resistir a uma inundação permanente de 2 a 3 anos sem maiores perdas. Somente depois de 4 anos de inundação permanente, maiores partes cia população começam a morrer, como foi observado durante o período de $1971-1974$, no qual o nível da água não baixou suficientemente. A maioria das espécies perde as suas folhas durante a inundação, porém algumas delas mantêm-nas também sob a água. Estas foihas parecem funcionar normalmente na próxima época seca até que sejam substituídas por folhas novas (Symmeria paniculata).

G período de produção de sementes coincide com a enchente, sendo a água essencial para a distribuição das sementes. Neste contexto, gostaríamos de focalizar a distribuição de sementes por peixes (ictiocoria), que é muito comum nas várzeas do Amazonas, demonstrando a interrelação íntima entre organismos aquáticos e organismos terrestres. Muitas espécies de peixes (p.ex. Brycon spp, Colossoma spp., Mylossoma spp) são frugívoros. Elas normalmente quebram as sementes (p.ex. sementes de palmeiras (Astrocaryum jauary), mas, às vezes, engolem-nas inteiras, transportando-as por grandes distâncias e defecando-as 
sem destruir sua capacidade de germinação (Gottsberger, 1978; Goulding, 1979) .

Considerando as adaptações mencionadas, surge a dificuldade de aplicar os termos "vegetação aquática" e "vegetação terrestre" às plantas da várzea. Já em lagos sem grandes flutuações de nível de água, a definição de plantas aquáticas e terrestres pode ser complicada, como demonstra Sculthorpe (1971: 3-10). Gessner (1955: 2) evitando a definição indica:

Uma definição estrita de uma planta aquática é difícil de encontrar, porque não somente as plantas aquáticas inferiores como as superiores são relacionadas por meio de várias transiçōes com plantas terrestres. Todavia, uma tal definição teria, principalmente, antes um valor terminológico do que um valor conceitual.

Considerando as condições ecológicas altamente complicadas descritas nestes parágrafos, temos que realmente perguntar se uma definição estrita da flora da várzea é realmente possivel ou necessária. Do ponto de vista limnológico, esta pergunta tem grande importância porque está relacionada a problemas de produção e de balanço de nutrientes na água. Isso será demonstrado mais tarde na discussão dos termos "material alóctone e maternal autóctone".

\section{A Fauna da Várzea}

A mudança entre a fase aquática e a fase terrestre afeta a fauna da mesma maneira drástica (Junk, 1976). Muitos animais têm a capacidade de evitar as condições desfavoráveis por ineio de migrações horizontais e verticais. Muitas espécies de peixes, o peixe-boi, as tartarugas e provavelmente algumas espécies de camarões, migram dentro do rio durante o nível baixo, para evitar a seca. Esta migração têm como consequêência uma mudança drástica dos seus biótopos e da oferta de ítens alimentícios. A maioria dos gimnotídeos vivem durante maior parte do ano protegidos entre árvores e arbustos submersos e na vegetação aquática. Durante a água baixa estas áreas, na sua maiorıa. são secas, forçando os peixes a desviarem-se para a área aberta, onde não há proteção. Os peixes são, por isso, mais atingidos por preda- ção € os espécimens coletados por nós durante esta época estavam freqüentemente feridos. Enquanto uma oferta grande de ítens alimentares está à disposição dos predadores, a oferta para espécies herbívoras é reduzida drásticamente, porque as macrófitas aquáticas e a floresta inundável estão secas. Durante esta época, estas espécies têm que viver principaimente da gordura estocada durante a época cheia. Muitas espécies reduzem, além disso, a aceitação de alimentação por causa do desenvolvimento das gônadas. É interessante verificar, que esta periodicidade parece atingir também algumas espécies carnivoras como, p.ex. as piranhas.

Além das migrações horizontais, verificamos também migrações verticais para evitar a seca, porém, naturaimente, em escala muito menor. As larvas do efemeróptero Asthenopus curtus, que brocam a madeira submersa, têm que sair dos seus túneis e migrar correspondentemente ao nível da água.

As migrações de desova das espécies de peixes são ligadas também às inundações. Durante a subida da água, estas espécies (Colossoma macropomum, Curimata spp., Prochilodus spp., etc.) migram dos lagos para os rios para desovar. Os ovos são transportados peia correnteza para dentro das áreas recém-inundadas, onde a água oferece condições de oxigênio suficientemente boas e bastante alimentação e proteção para os alevinos. A movimentação do rio ábaixo de ovos e alevinos é compensada durante a cheia por grandes migrações rio acima dos espécimens mais velhos na procura de melhores lugares para alimentarem-se (Goulding, 1979).

As flutuações do nível de água têm conseqüências catastróficas para animais com mobilidadie limitada. As populações são reduzidas, periodicamente, ao mínimo (Junk, 1976; Irmler, 1976). Estes animais mostram ciclos de vida curtos e altas taxas de reprodução, tais como os Naidídeos (reprodução por divisão), o efemeróptero Brasiliocaenis irmleri (Irmler, 1975), o caramujo Pomacea lineata (Eckel, 1975), os chironomideos Chironomus strenzkei (Fittkau, 1968) e Goeldichironomus pictus (Reiss 1976) e o efemeróptero Asthenopus curtus (Braga, 1979), para mencionar alguns exemplos. 
De acordo com Pianka (1970), estes organismos são incluídos na categoria dos r-estrategistas, especializados em colonizar biótopos recém-desenvolvidos, por meio de taxas de reprodução extremamente altas e ciclos de vida curtos. Lowe-McConnell (1964) sugere que estratégias similares encontram-se também em várias espécies de peixes amazônicos.

Muito comum são também estágios de iatência, tais como a diapausa do bivalvo Eupera simoni, gêmulas das esponjas Drullia sp., Trochospongilla spp. e Metania sp. (Irmler, 1975 e $\mathrm{s} / \mathrm{d}$ ) e efípios em muitos cladóceros planctônicos e perizóicos. Especialmente em relação a animais de baixa mobilidade e hidrófitas, pode comprovar-se, em parte, uma certa afinidade entre as condições ecológicas de áreas alagáveis com as condições das águas temporárias.

Com o decorrer da enchente, os organismos aquáticos encontram condições cada vez mais favoráveis, enquanto a situaçẫo para os organismos terrestres piora. Como foi demonstrado para os animais aquáticos, entre os organismos terrestres também ocorrem migrações horizontais e verticais para evitar a inundação (Irmler, 1979 a; Adis, 1979): o estafilinídeo Lathrobium sp. acompanha as flutuações do nível de água na beira por algumas centenas de metros. Os colêmbolos são capazes de acompanhar a mudança da beira somente em pequena escala de cerca de $5 \mathrm{~m}$ (Beck, 1976). Muitos invertebrados mostram migrações verticais entre o solo e a copa das árvores da floresta inundável, modificando para isso até o seu comportamento. Os opilionídeos por exemplo, mostram uma fototaxia negativa durante a seca e uma fototaxia positiva durante a cheia facilitando-lhes a procura da copa das árvores (Irmler, 1975).

Estágios de latência também são comuns, p.ex. para a barata Epilampra irmleri, o oribatídeo Eremobelba foliata, e vários colêmbolos (Beck, 1969 e 1976; Irmler, s/d). Porém, um grande número de animais é inundado durante cada enchente, servindo como fonte alimentar importante para predadores aquáticos, como p.ex., os peixes. Isso novamente demonstra a interrelação intensa entre os habitats terrestres e aquáticos.
Além da fauna diretamente atingida pela flutuação do nível, têm que ser mencionados os animais indiretamente influenciados por este fenômeno. Muitos animais terrestres coIonizam a vegetação aquática e a usam como fonte alimentar, tais como o gafanhoto Paullinia acuminata, que vive sobre Salvinia spp., Pistia stratiotes e Azolla sp., o gafanhoto Cornops longicorne e o curculionideo Neochetina bruchi, que comem Eichhornia crassipes (Bennett \& Zwölfer, 1968). Estes animais possuem também adaptações para a vida aquática. Paullinia acuminata e Cornops longicorne podem nadar e também esconder-se sob a superfície da água. Os ovos são depositados sob a superfície da água, nas partes inferiores das folhas (Paullinia) ou sob a superfície da água, dentro dos pendúnculos das folhas (Cornops; Neochetina). Quando as plantas morrem durante a seca, estas populações são reduzidas também drásticamente. Ainda não se sabe até que ponto existem adaptações similares na fauna que permanece constantemente na copa das árvores da floresta inundada. Porém, é de esperarse que estes animais também sejam atingidos de um certo modo, porque muitas espécies de árvores perdem as folhas durante a cheia.

\section{PRODUÇÃO E DECOMPOSIÇÃO}

Como já foi demonstrado, uma alta capacidade de reprodução é uma adaptação muito comum e importante para as condições permanentemente variáveis da várzea. Em conseqüência disso, há alta produção, porém há também grandes perdas durante a fase desfavorável. Além da capacidade de reprodução, a disponibilidade de nutrientes é essencial para uma produção alta.

Durante a enchente, o rio invade a várzea, trazendo nutrientes, tanto dissolvidos, quanto em partículas. Um período de alta produção ccmeça para os organismos aquáticos. Schmidt (1973a), estudando o fitoplâncton do lago Castanho na várzea perto de Manaus, calcula uma produção anual de $6 \times 10^{3} \mathrm{~kg}$ de matéria seca/ ha e um período de "turnover" de 1,7 dias. Este valor não pode ser considerado representativo para toda a várzea, porque em algumas áreas a concentração de fitoplâncton é permanentemente diluída pela água do Solimões, que 
pode ser considerada como muito pobre em algas planctônicas. Além disso, o epilimnion crescente aumenta permanentemente a área à disposição do fitoplâncton. Os estudos de Fisher (1978) no lago do Castanho mostram uma zona de alta produção de fitoplâncton na área onde a água do lago e a água do rio se misturam. Tanto os trabalhos de Schmidt, quanto de Fisher foram realizados no meio dos lagos, onde não há sombra. Howard-Williams (1977) mostra que em pântanos tropicais a produção primária na água é reduzida por causa de macrófitas emersas. Isso também vale para as regiões da várzea cobertas com floresta de inundação ou macrófitas aquáticas flutuantes, ou onde a transparência da água é reduzıda dada a substâncias húmicas coloridas em solução ou partículas inorgânicas em suspensão. Supomos que a produção primária pelo fitoplâncton na várzea varia conforme as mudanças constantes das condições hidrológicas e das diferenças locais das condiçöes físico-químicas. Por isso, lagos de várzea parecem ser muito mais variáveis de que lagos clássicos.

As macrófitas aquáticas mostram alta produtividade, e o aumento da sua biomassa pode chegar até $3000 \%$ /mês como foi medido para Salvinia auriculata (Junk \& Howard-Williams, dadcs não publ.). Os nutrientes necessários para este crescimento são absorvidos tanto do fundo do lago, quanto diretamente da água, de partículas inorgânicas e substâncias dissolvidas. Grandes quantidades de nutrientes são capturadas desta maneira pelas enormes quantidades de macrófitas aquáticas (Howard-Williams \& Junk, 1977). Isso é especialmente importante para o potássio e o fósforo, que ocorrem em concentrações muito baixas na água sendo, provavelmente, limitantes para a produçăo primária (Tab. 1) .

Uma transferência de nutrientes entre a água e os sedimentos por meio de macrófitas aquáticas já foi descrita por Prentki et al. (1978), Klopatek (1978) e outros. Em áreas inundáveis, encontramos um mecanismo de transferência adicional da fase aquática para fase terrestre e vice-versa. Durante a vazante uma parte da vegetaçăo flutuante é transporta-
TABELA 1 - Concentraçōes de nutrientes em plantas aquáticas do Médio Amazonas em comparação com concentraçōes de nutrientes na água de um lago "típico" da várzea. (Conforme Howard-Williams \& Junk, 1977).

\begin{tabular}{lccc}
\hline & $\begin{array}{c}\text { água do } \\
\text { lago } \\
\text { Kg.ha-1 }\end{array}$ & $\begin{array}{c}\text { plantas } \\
\text { aquáticas } \\
\text { Kg.ha-1 } \cdots\end{array}$ & $\begin{array}{c}\text { Relação } \\
\text { planta/água }\end{array}$ \\
\hline Sódio & 55 & 41 & 0,75 \\
Potássio & 45 & 356 & 7.9 \\
Manganês & 66 & 28 & 0,42 \\
Cálcio & 203 & 83 & 0,41 \\
Silício & 25 & 151 & 6,0 \\
Fósforo (total) & 5,3 & & 3,6 \\
Fósforo (livre) & 0,3 & 19 & 63,3 \\
Nitrogênio (total & 75 & 196 & 2,6 \\
Nitrogênio (livre) & 0,3 & & 653
\end{tabular}

da da várzea para o rio, entrando na sua rede alimentar, porém a maior parte das plantas seca nas beiras e no fundo exposto dos lagos (cerca de $10^{4} \mathrm{~kg}$ matéria seca/ha da área coberta por plantas aquáticas). Ali se decompõem, e os nutrientes podem ser utilizados pela vegetação terrestre, que rapidamente invade estas áreas $\left({ }^{6}\right)$. Assim, as macrófitas aquáticas têm um importante papel na transferência de nutrientes e energia da fase aquática para a fase terrestre. Eles podem ser considerados como fertilizadiores naturais para a vegetação terrestre. Este efeito foi demonstrado por Noda et al. (1978), que usaram macrófitas aquáticas para adubar feijão-de-asa com bastante êxito. Há outros experimentos deste tipo em vários países tropicais (Little, 1968; Kamal \& Little, 1970, etc.).

(6) - Durante a seca, o fogo pode ter uma grande impor tância na destruição do material orgânico (Welcomme, compess.). 
Altas taxas de produção encontram-se também na vegetação terrestre. Paspalum fasciculatum, um capim comum, chega a produzir $3 \times$ $10^{4} \mathrm{~kg}$ material seca/ha durante um período de 8 meses. Durante a cheia, cerca da metade deste material decompõe-se e volta para a fase aquática. (Junk \& Howard-Williams, dados não publ.). A metade restante sobrevive à cheia $\mathrm{e}$ começa a brotar na próxima seca novamente.

Desta maneira, nutrientes vão sendo acumulados dentro do sistema até atingir um equilíbrio dinâmico - " pulse stability" - COdum, 1959j. Além disso, provavelmente circulam mais nutrientes dentro do sistema de que se poderia supor, considerando somente a quantidade de nutrientes entrando com a água do Solimões pela enchente. Uma acumulação de nutrientes pela vegetação já foi descrita para a floresta tropical da terra firme amazônica (Fittkau, 1973; Klinge, 1973). Ainda que os mecanismos em ambos os sistemas sejam diferentes, o efeito é similar.

Os processos de decomposição funcionam muito rapidamente, o que é de esperar-se considerando as altas temperaturas de cerca de $30^{\circ} \mathrm{C}$. Plantas herbáceas perdem cerca de $50 \%$ da matéria seca durante as primeiras duas semanas na fase aquática (Howard-Williams \& Junk, 1976). As folhas das árvores da floresta inundável decompõem-se mais devagar dada a alta percentagem de material das paredes celulares. A decomposição de madeira é acelerada pela atividade da larva de Asthenopus curtus (Ephemeroptera), que normalmente broca madeira morta, aumentando desta maneira a superfície para o ataque de fungos e bactérias. Porém, a decomposição total das plantas depende ainda da fase terrestre. A boa aeração do solo e o desenvolvimento de uma fauna diferente aceleram a decomposição, inibindo o acúmulo de grandes quantidades de material orgânico. Por isso, apesar da existência de grandes áreas inundáveis na região amazônica, não há grandes depósitos de turfa, o que é encontrado freqüentemente em outras regiões tropicais com pântanos permanentes (Nikonov \& Sluka, 1964). A suposição de que a mudança entre a fase aquática e a fase seca seja o fator decisivo para isso, é confirmada pela existência de pequenas áreas pantanosas na várzea, nos quais, por causa da morfologia da bacia hidrográfica, não ocorre seca. $\mathrm{O}$ oxigênio falta permanentemente e ilhas flutuantes são formadas pela vegetação que podem ser comparáveis com turfa (Junk, s/d) .

Nas discussões sobre produção e decomposição, o limnólogo focaliza sempre a origem do materiai orgânico, classificando-o como alóctone ou autóctone. As condições ecológicas descritas para a várzea não permitem isso no sentido clássico. Conseqüentemente, também 0 problema do ciclo de nutrientes não pode ser resolvido no sentido clássico. Como, por exemplo, c capim comum, a Canarana (Echinochloa polystachya), poderia ser incluído no cálculo do balanço dos nutrientes? Ele está enraizado no fundo do lago. Durante a fase aquática, ele produz raizes nos nós para absorver nutrientes dissolvidos na água. Durante a seca, uma parte das plantas morre, mas começa a crescer com as chuvas, absorvendo nutrientes do "fundo do lago" seco (que mais tarde se tornará o litoral ou até o profundal do futuro lago) sendo um membro importante da comunidade vegetal terrestre, e forma na cheia novamente uma parte importante da vegetação aquática. Este problema somente pode ser resolvido quando consideramos o ciclo de nutrientes em áreas alagáveis como uma unidade funcional, apesar da mudança entre a fase aquática e a fase terrestre (Fig. 4). Sob este ponto de vista, áreas inundáveis são bem diferentes dos sistemas clássicos de águas paradas e águas correntes.

\section{REDES ALIMENTARES NA VÁRZEA}

A interação íntima do meio ambiente aquático e terrestre é refletida também na estrutura das redes alimentares. A importância da floresta inundável como fonte alimentícia para os peixes, já foi mencionada no capítulo anterior. Do mesmo modo, as macrófitas aquáticas e terrestres servem como ítens alimentares importantes para muitos animais aquáticos e terrestres. Existem várias espécies de peixes herbivoros, que ocorrem em grandes quantidades, como muitos membros da Família Anostomidae (Leporinus frederici, Schizodon fascia- 


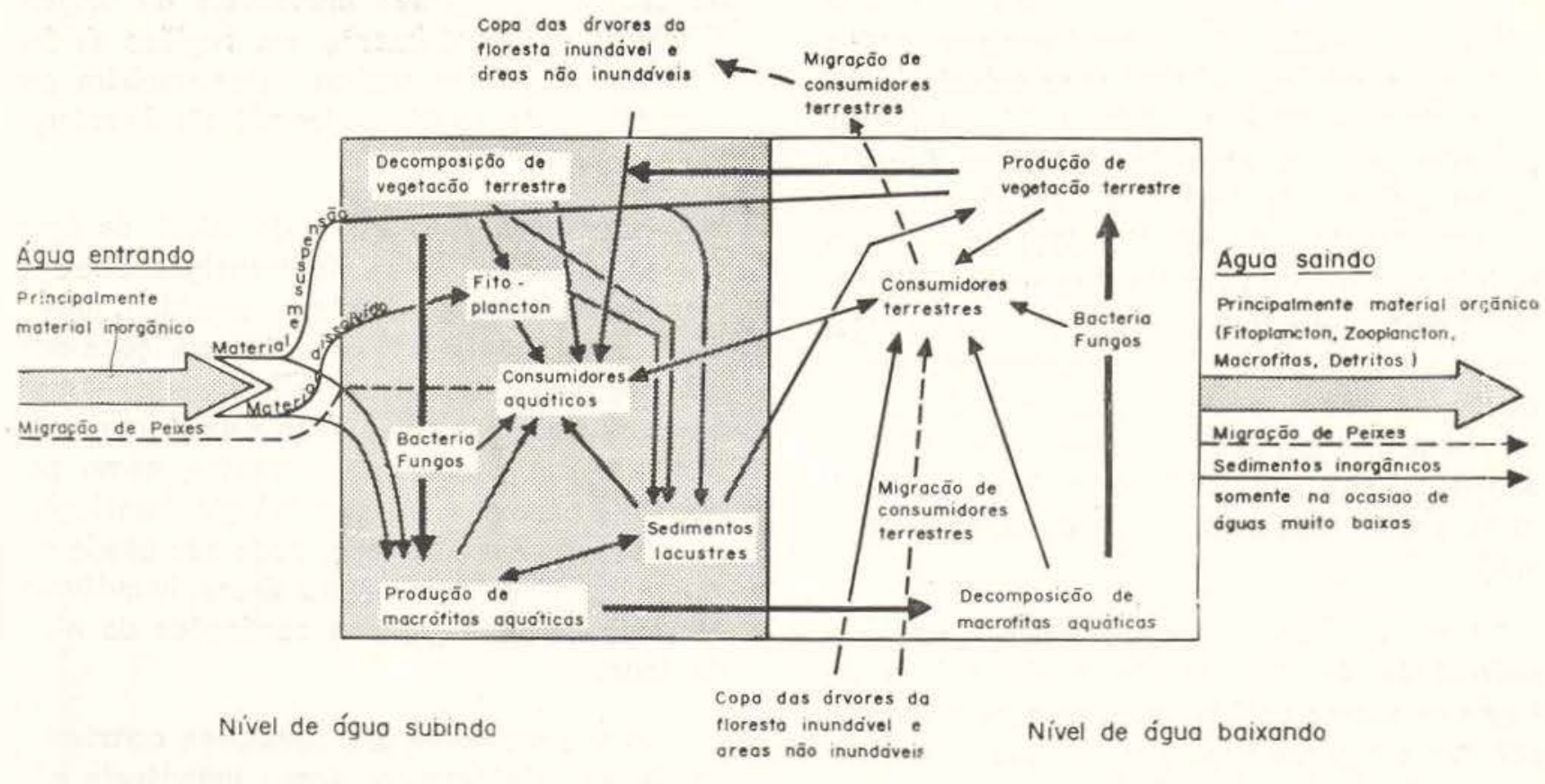

Fig. 4 - Modelo do ciclo de nutrientes e redes alimentares na várzea do Médio Amaonas durante a cheia e a seca.

tus, Rhytiodus microlepis) (Santos, 1979)). Outros importantes herbívoros são o peixe-boi (Trichechus inunguis), a capivara (Hydrochoerus hydrochoeris) e as tartarugas (Podocnemis spp). Antigamente, estas espécies ocorriam em grandes números. Porém, desde o século passado, o seu número diminuiu drasticamente por causa da caça e pesca intensiva. Em conseqüência disso, um importante elo na rede alimentar foi modificado e aparentemente, uma grande parte de plantas aquáticas de alta qualidade nutritiva não está sendo mais utilizada por animais superiores.

A importância de macrófitas aquáticas para invertebrados terrestres já foi mencionada nos capítulos anteriores. Quanto aos invertebrados aquáticos Junk (1973) indica que os mesmos usam este material e o detrito orgânico grosso somente de uma maneira limitada. Perifiton, fitoplâncton e detrito fino capturados entre as raízes das plantas parecem ser de maior importância para a alimentação do Perizoon.

Como já foi mencionado, a produção primária pelo fitoplâncton tem que ser considerada de baixa importância para grandes áreas da várzea por causa da baixa iluminação. Schmidt (1973b) e Schmidt \& Uherkovich (1973) indicam que as cianofíceas são muitas vezes os representantes dominantes da comunidade fitoplanctônica. O seu valor como fonte alimentícia para o zooplâncton parece ser baixo (Brandorff, 1977) e, provavelmente, também muitos outros animais não podem aproveitá-las. Brandorff (lbid.) discute neste contexto a importância do detrito orgânico fino e das bactérias e fungos associados com este substrato como fonte alimentar para o zooplâncton.

Várias espécies de peixes zooplanctófagos são conhecidos da várzea (p.ex. Colossoma macropomum, Hypophthalmus edentatus, Triportheus culter) (Honda, 1974; Carvalho, 1980; Almeida, 1980). Zooplâncton, perifiton, perizoon e, até um certo ponto, fitoplâncton devem ter uma importância alta nas redes alimentares, descle consumidos pelos juvenis de muitas espécies de peixes, que mais tarde passam para uma alimentação diferente.

Conforme Irmler (1979 b), detrito, existindo em grandes quantidades, é de grande importância para as redes alimentares terrestres durante a seca no igapó do rio Negro. Dados adicionais da floresta da várzea sugerem condi- 
ções similares. Conforme Howard-Williams (1977), redes alimentares em áreas pantanosas tropicais sombreadas baseiam-se principalmente no detrito. Fittkau (1973) e Klinge (1973) encontraram uma situação similar na floresta da terra firme da Amazônia. As observações de Junk (1973) e Brandorff (1977) com respeito à importância do detrito fino para a alimentação do perizoon e zooplâncton foram do mesmo modo confirmadas para vertebrados. Investigações sobre o conteúdo estomacal de peixes mostram que um grande número de espécies são micrófagas ou detritívoras (por ex. Curimata spp, Prochilodus spp., Semaprochilodus spp) .

Concluindo, podemos dizer que o tipo e a quantidade de alimentação à disposição da fauna na várzea está constantemente mudando, por causa das constantes mudanças das condições hidrológicas. As adaptações morfológicas e etológicas da fauna para esta situação ecológica específica serão compreensíveis somente quando houver dados à disposição, incluindo o ciclo anual inteiro. Neste contexto, gostariamos de acentuar a necessidade de estudos durante condições hidrológicas extremas, quando aparecem as maiores diferenças na oferta de alimentação forçando os organismos a utilizar a capacidade inteira das adaptações existentes.

\section{ÁREAS INUNDÁVEIS - ECOSSISTEMAS ESPECÍFICOS}

Considerando as informações sobre a várzea, tomada como exemplo para áreas inundáveis, chegamos à conclusão de que existem as seguintes diferenças entre elas e os lagos e rios considerados como sistemas clássicos, estabelecidos na Limnologia.

Áreas inundáveis estão sujeitas a inundações periódicas. A grande maioria está em estreitos contatos com rios, trocando água com eles, retendo respectivamente uma parte da água nos rasos "lagos de várzea" permanentes ou temporários (áreas inundáveis de origem fluvial) $\left({ }^{7}\right)$. Especialmente em regiōes áridas e semi-áridas, elas podem estar também em contato com lagos (áreas inundáveis de origem lacustre) .

As grandes flutuações do nível de água produzem largas áreas de transição entre o sistema terrestre e o sistema aquático, provocando constantes mudanças das condições ecológicas. Isso difere áreas inundáveis de outras áreas de transição entre o meio ambiente aquático e o meio ambiente terrestre, como por exemplo, pântanos. A terminologia limnológica relacionada com o espaço, pode ser usada somente com restrições para áreas inundáveis, por causa destas grandes oscilações do nível de água.

Em conseqüência das condições constantemente em mudança, as áreas inundáveis não mostram uma estrutura uniforme. Elas são subdivididas em um mosaico de biótopos. Durante a fase aquática, estes biótopos podem ser submetidos adicionalmente a fortes mudanças em pequena escala relativamente aos seus parâmetros físico-químicos.

Quanto ao balanço dos nutrientes, as áreas inundáveis podem ser consideradas comc sistemas intermediários entre lagos, que atuam como sistemas fechados com caráter acumulativo, e rios, que funcionam como sistemas abertos com caráter transportativo (Reiss, 1976). Ao contrário das águas temporárias, áreas inundáveis ficam em contato estreito com rios ou lagos, tanto em relação à sua biocenose quanto ao balanço de nutrientes.

Nutrientes, principalmente em forma inorgânica, tanto dissolvidos quanto em suspensão, entram nas áreas inundáveis. Ali uma parte dos nutrientes é incorporada à vegetação aquática e terrestre e entra nas redes alimentares das áreas inundáveis. Mais tarde, eles voltam em parte para o rio ou lago sob a forma de matéria orgânica (plantas aquáticas, animais, detrito orgânico e substâncias orgânicas em solução), influenciando consideravelmente a

(7) - Áreas inundáveis ao longo dos trechos inferiores de rios, provocadas pela atividade da maré, poderiam ser consideradas como forma específica de áreas inundáveis de origem fluvial (áreas inundáveis de origem fluvial influenciadas pela atividade da maré). 
TABELA 2 - Comparaçẫo dos ecossistemas : lago, área inundável e rio.

\begin{tabular}{c|c|c|c|c|}
\hline & AREA INUNDAVEL & LAGO & Intermediário \\
\hline$v$ & Água Parada & Água Corrente \\
\hline
\end{tabular}

Tipo de Corpo de água

Correnteza de baixa importância.

Perene.

Nivel de água

Biótopos

Organismos colonizadores

Redes alimentares

\section{Condiçōes de Oxigênio}

Adaptaçōes da fauna para concentraçôes baixas de $\mathrm{O}_{2}$

Divisâo espacial em biótopos

Transiçāo entre o meio ambiente terrestre e aquático

Tipo de sistema

Ciclo de nutrientes

Na sua maioria aquáticos.

Na sua maioria aquáticos. epilimnio.

Ocorrendo. ginal bem determinada.

Bem definido, constante. acumulativo.
Dependendo geralmente do lençol freático, às vezes da precipitaçâo e de rios, em geral relativamente constante.

Baseados em sua maioria em material autóctone, principalmente fitoplâncton.

Normalmente favoráveis, pelo menos no

Reduzida para uma pequena área mar-

Na sua maioria fechado, com caráter

Ciclos próprios internos, influenciados em geral unidirecionalmente pela terra. com exceçẫo de áreas inundáveis ligadas. fase complementar respectiva.
Correnteza variável e de importância local, em grandes áreas de baixa importância.

Intermediário entre perene e temporário.

Correnteza unidirecional de importância decisiva.

Normalmente perene.

Dependendo geralmente de rios e lagos. sujeito a grandes oscilações.

Biótopos de transição aquáticos/terres. tres.

Aquáticos e terrestres. Muitos organismos com adaptaçôes para a vida na

Baseados em sua maioria em material e detrito da vegetaçăo superior crescendo tanto na fase terrestre quanto aquática.

Em regiōes tropicais muitas vezes desfavoráveis, e em certas áreas muito desfavoráveis.

Ocorrendo em grande número.

Constantemente mudando.

Cobrindo grandes áreas, difícil de determinar, constantemente mudando.

Intermediário.

Fortes interrelações entre a fase aquática e a fase terrestre e entre a área inundável e o rio ou lago em conexão.
Dependendo geralmente da precipitaçăo e do lençol freático, sujeito a grandes oscilações.

Na sua maioria aquáticos.

Na sua maioria aquáticos.

Baseado principalmente em material alóctone.

Favoráveis. ros reduzidos.

Bem definido, em parte mudando.

Reduzida a uma beira bem determina da, às vezes mudando.

Aberto, com caráter de descarga.

Principalmente influenciado pela terra, influências ao meio ambiente terrestre existentes e bem desenvolvidas em combinaçāo com áreas inundáveis.
Nāo ocorrendo ou ocorrendo em núme- 
sua biocenose. $\mathrm{Na}$ área inundável ocorre uma transferência importante de nutrientes entre a fase aquática e a fase terrestre, especialmente por meio de macrófitas aquáticas. Isso pode provocar um acúmulo considerável de nutrientes, até que se atinja um equilíbrio dinâmico. Em conseqüência disso, o sistema pode funcionar num nível trófico mais elevado, tendo à disposiçäo os nutrientes que circulam dentro do próprio sistema, e adicionalmente os nutrientes introduzidos pela enchente.

Os organismos que colonizam as áreas inundáveis são em parte aquáticos, em parte terrestres e intermediários, mostrando adaptações morfológicas, fisiológicas e/ou etológicas para sobreviver à fase aquática e terrestre, respectivamente.

As mudanças ecológicas drásticas provocadas pela mudança entre a fase aquática e a fase terrestre provocam a produção de grandes quantidades de detrito orgânico pela vegetação decomposta, tanto aquática como terrestre. Por isso, o detrito é de grande importância para as redes alimentares. Porém a oferta de itens alimentares varia muito durante o ano tanto em quantidade quanto em qualidade. Relativamente ao seu nível de organização, as áreas inundáveis têm que ser consideradas como sistemas de baixa maturidade (Margalef, 1968) .

Embora as áreas inundáveis, do ponto de vista funcional, possam ser bem diferenciadas dos sistemas de água parada e água corrente. espacialmente elas não podem ser separadas claramente porque sua própria existência depende dos rios e lagos, com os quais mantém limites flexiveis. Teoricamente, cada corpo de água possui áreas inundáveis. Porém as peculiaridades destas áreas somente aparecem claramente quando o seu tamanho é bastante grande, reduzindo suficientemente a influência direta dos sistemas puramente aquáticos e terrestres, respectivamente.

Em conclusão, podemos dizer que, baseando-se na quantidade de diferenças funcionais em relação aos rios e lagos, as áreas inundáveis deveriam ser consideradas como ecossistemas específicos (Tab. 2). Para elaborar as informações necessárias para a descrição minuciosa destes sistemas, os limnólogos têm que realizar muito mais estudos em áreas inundáveis, focalizando especialmente a mudança entre a fase aquática e a fase terrestre. Essa tentativa necessita de uma rediscussão da terminologia existente e novas metodologias, que permitam englobar a fase terrestre completamente nos estudos. Citando Thienemann: Os limnólogos têm que ir para a terra.

\section{Agradecimentos}

O trabalho de campo foi realizado em cooperação entre o instituto Nacional de Pesquisas da Amazônia - INPA, Manaus, Brasil, e o Institutc Max-Planck para Limnologia, Departamento de Ecologia Tropical, Plön, Alemanha. Agradeço a ambas instituiçōes pelo financiamento dos trabalhos, assistência técnica e colaboração. Agradeço especialmente aos meus colegas Dra. Karin Furch, Dr. Hans Klinge e Dr. Ulrich Irmler e à minha esposa Karola pelas discussões, críticas e comentários altamente válidos do manuscrito. A correção de português foi feita pelo Dr. Herbert Schubart. O manuscrito foi datilografado por minha secretária Elci Batista da Silva. A todos os meus sinceros agradecimentos.

\section{SUMMARY}

Difficulties arise during limnological investigations on the floodplains of the Middle Amazon, the so-called várzea, when the concepts, terminology and methodology of classical standing water and flowing water systems are applied. The pronounced periodical water level fluctuations, in combination with large-scale alternations between aquatic and terrestrial phases, produce ecological conditions which correspond neither to lakes and rivers nor to swamps or temporary water bodies.

A survey of the limnological and ecological literature shows a notable lack of studies on the landwater relationships, including those related to the terrestrial and aquatic phases characteristic of floodplains. There are several reasons for this, including the great complexity of the floodplain system, and a certain overlap between limnology and terrestrial ecology which has led to a neglect by both.

The ecological conditions of floodplains are described, using the várzea as an example, and the impact of the alternations between the land and water phases on fauna, flora and nutrient balance is discussed. Emphasis is given to the fact that floodplains are special ecsystems different from standing and flowing water bodies. 


\section{BIBLIOGRAFIA}

ADIs, J.

1979 - Vergleichende ökologische Studien an der terrestrischen Arthropodenfauna zentralamazonischer Überschwemmunbngswälder. Diss. Univ. Ulm. 99 p.

Almetda, R.G.

1980 - Aspectos taxonômicos e hábitos alimentares de três espécies de Triportheus (Pisces: Characoidei, Characidae) do lago do Castanho, Amazonas. Tese de Mestrado. INPA/FUA, Manaus, $104 \mathrm{p}$.

BECK, L.

1969 - Zum jahreszeitlichen Massenwechsel zweier Oribatidenarten (Acari) im neotropischen Überschwemmungswald. Verb. dtsch. zool. Ges. Innsbruck: 535-540.

1976 - Zum Massenwechsel der Makro-Arthropodenfauna des Bodens in Öberschwemmugswäldern des zentralen Amazonasgebiets Amazoniana, 6 (1): $1-20$.

BENNETT, F.D. \& ZWÖLFER, H.

1968 - Report on a survey of insects and mites associated with water hyacinth, Eichhornia crassipes in northern South America undertaken in February-March, 1968. Commonwealth Institute of Biological Control, Trinidad, $29 \mathrm{p}$.

Birge, E.A. \& JudAy, C.

1911 - The inland lakes of Wisconsin. The dissolved gases of the water and their biological significance. Bull. Wis. Geol. Nat. Hist. Survey, 22, Sci Ser. 7, 259 p.

BRAGA, R.A.P.

1979 - Contribuição à ecologia de Asthenopus curtus Hagen (Insecta - Ephemeroptera) dos arrediores de Manaus (Amazôna Central). Tese de Mestrado, INPA/FUA, Manaus, $70 \mathrm{p}$

BRANDORFF, G.O.

1977 - Untersuchungen zur Populationsdynamik des Crustaceenplanktons im tropischen Lago Castanho (Amazonas Brasilien). Diss. Univ. Kiel, 108 p.

BRUNDIN, L.

1956 - Die bodenfaunistischen Seetypen und ihre Anwendbarkeit auf die Südhalbkugel. Zugleich eine Theorie der produktionsbiologischen Bedeutung der glazialen Erosion. Rep. Inst. Freshw. Res. Drottningholm, 37: 186. 235.

Carvalho, FM.

1980 - Estudo da alimentação, desenvolvimento dos ovários e composição quimica de Hypophthalmus edentatus Spix, 1829 e Potamorhina pristigaster Steindachner, 1878 (Pisces, Ostariophysi) do lago do Castanho, AM, Brasil. Tese de Mestrado, INPA/FUA, Manaus.

Caspers, H. \& Schultz, H.

1960 - Studien zur Wertung der Saprobiensysteme. Int. Rev. Hydrobiol., 45 (4): 535-565.

Castro Soares, L.

1956 - Excursion guidebook 8: Amazonia. International Geographical Union, Brazilian National Committee. Rio de Janeiro, $216 \mathrm{p}$.

DISTER, E.

1980 - Geobotanische Untersuchngen in der hessischen Rheinaue als Grundlage für die Naturschutzarbeit. Diss. Univ. Göttingen, $170 \mathrm{p}$.

ECKELL, R.

1975 - Öko-physiologische Untersuchungen zur Atmung-und Kalkstoffwechselphysiologie von Pomacea lineata (Ampullariidae). Diss. Univ. Kiel, $110 \mathrm{p}$.

ELSTER, H.J.

1956 - Einige Gedanken zum weiteren Ausbau des Seetypensystems. Zeitschrift für Fischerei und deren Hilfswissenschaften, 5 (5/8); 531 . 537.

1958 - Das limnologische Seetypensystem, Rückblick und Ausblick. Verh. Internat. Verein. Limnol., 13: 101-120.

1962 - Seetypen, Fliessgewässertypen und Saprobiensystem. Int. Revue ges. Hydrobiol, 47 (2): 211-218:

1966 - Über die limnologischen Grundlagen der biologischen Gewässer-Beurteilung in Mitteleuropa. Verh. Internat. Verein. Limnol., 16: 759-785.

FAIRBRIDGE, R.W.

1961 - Eustatic changes in sea level. Physics and Chemistry of the Earth, 4: 99-185.

FISHER, T.R.

1978 - Plancton e produção primária em sistemas aquáticos da Bacia da Amazônia Central. Acta Amazonica, 8 (4): 43-54.

Fitrkau, E.J.

1968 - Chironomus strenzkei n. sp. [Chironomidae, Dipt.), ein neuses Laboratoriumstier. Morph. Ökol. Tiere, 63: 239-250.

1973 - Artenmannigfaltigkeit amazonischer Lebensräume aus ökologischer Sicht. Amazoniana, 4 (3): $321-340$.

FORBES, S.A.

1887 - The lake as a microcosm. Bull. Peoria (IIlinois Sci. Assoc.): 77-87.

FOREL, F.A. 1892-1901 - Le Léman. Monographie limnologique. 3 vols., F. Rouge, Lausanne. 
1901 - Handbuch der Seekunde. Allgemeine Limnologie. J. Engelhorn, Stuttgart.

GESSNER, F.

1955 - Hydrobotanik. Band I: Energiehaushalt. VEB Deutscher Verlag der Wissenschaften. Berlin, $517 \mathrm{p}$.

GOSSELINK, J.G. \& TURNER, R.E.

1978 - The role of hydrology in freshwater wetland ecosystems. In: Freshwater Wetlands, Ecological Processes and Managment Potential. Goad, R.E.; Whigham, D.F.; Simpson, R.L., Ed., p. $63-78$

GoTTSBERGER, G.

1978 - Seed dispersal by fish in the inundated re. gions of Humaitá. Biotropica, 10 (3): 170 . 183.

GOULDING, W.M

1979 - Ecologia de pesca do Rio Madeira. INPA. Manaus, $172 \mathrm{p}$.

HASLER, A.D.

1974 - Coupling of lang and water systems. Springer Verlag, Heidelberg, 352 p.

HeCKMAN, C.W.

1979 - Rice-field-ecology in northeastern Thailand. Dr. W. Junk Publishers, The Hague, Boston - London, 228 p.

HEJNY, $\mathbf{S}$,

1960 - Ökologische Charakteristik der Wasser und Sumpfpflanzen in den slowakischen T:efebenen (Donau-und Theissgebiet). Verlag der slowakischen Akademie der Wissenschaften, Bratislava, $487 \mathrm{p}$.

HONDA, E.M.S.

1974 - Contribuiçăo ao conhecimento da biologia de peixes do Amazonas. 2. Alimentação do tambaqui, Colossoma bidens (Spix). Acta Amazonica, 4 (2): 47-53.

Howard-WiLliams, C.

1977 - Swamp ecosystems. The Malayan Nature Journal, 31 (2): 113-125

Howard-Williams, C. \& JUNK, WJ.

1976 - The decomposition of aquatic macrophytes in the floating meadows of a Central Amazonian várzea lake. Biogeographica, 7: 115 . 123.

1977 - The chemical composition of Central Amazonian aquatic macrophytes with special reference to their role in the ecosystem. Arch. Hydrobiol., 79 (4): $446-464$.

Hutchinson, G.E.

1957 - A treatise on limnology. New York. John Wiley Sons. V. 1, $1015 \mathrm{p}$

Hutchinson, G.E. \& LÖFfLER, H.

1956 - The thermal classification of lakes. Proc. Nat. Acad. Sci. Wash., 42: 84-86.
HYNES, H.B.N.

1972 - The ecology of running waters. Liverpool. Liverpool University Press, $555 \mathrm{p}$.

ILLIES, J.

1953 - Die Besiedlung der Fulda (insbes. das Benthos der Salmonidenregion) nach dem jetai. gen Stand der Untersuchung. Ber. Limnol. Flusstation Freudenthal, 5: 1-28.

1955 - Der biologische Aspekt der limnologischen Fliesswässertypisierung. Arch. Hydrobiol. Suppl., 22: 337-346.

1961 - Versuch einer allgemeinen biozönotischen Gliederung der Fliessgewässer. Int. Revue ges. Hydrobiol., 46 (2): 205-213.

Illies, J. \& SCHWABE, G.H.

1959 - Limnologie und Ökologie. Biologisches Zen. tralblatt, 78 (2): $391-396$.

ILLIES, J. \& BOTOSANEANU, L.

1963 - Problemes et méthodes de la classification et de la zonation écologique des eaux courantes, considerées surtout du point de vue faunistique. Mitt. Internat. Verein. Limnol., 12: 1-57.

IRMLER, U.

1975 - Ecological studies of the aquatic soil invertebrates in three inundation forests of Central Amazonia. Amazoniana, 5 (3): 337-409.

1976 - Zusammensetzung, Besiedlungsdichte und Biomasse der Makrofauna des Bodens in der emersen und submersen Phase zentralamazonischer Oberschwemmungswälder. Biogeographica, 7: 79-99.

1979a - Abundance fluctuations and habitat changes of soil beetles in Central Amazonian inundation forests (Coleoptera: Carabidae, Staphylinidae). Studies on Neotropical Fauna and Environment, 14: 1-16.

$1979 \mathrm{~b}-$ Considerations on structure and function of the "Central Amazonian inundation forest ecosystem" with particular emphasis on selected soil animals. Oecologia, 43: 1-18.

$\mathrm{s} / \mathrm{d}$ - Oberlebensstrategien von Tieren im saisonal überschwemmten amazonischen Oberschwemmungswald. (no prelo)

JUNK, W.J.

1970 - Investigations on the ecology and production-biology of the "floating meadows" (Paspalo-Echinochloetum) on the Middle Amazon. 1. The floating vegetation and its ecology. Amazoniana, 2 (4): 449-495.

1973 - Investigations on the ecology and production-biology of the "floating meadows" (Paspalo-Echinochloetum) on the Middle Amazon. II. The aquatic fauna in the root zone of floating vegetation. Amazoniana, 4 (1): 9-102.

Áreas... 
1976 - Faunal ecological studies in inundated areas and the definition of habitats and ecological niches Animal Research and Development, 4: 47-54.

$\mathrm{s} / \mathrm{d}$ - Ecology of swamps of the Middle Amazon. In: Goodall, D.W. (ed.): Ecosystems of the world. Amsterdam. Elsevier Scientific Publishing Company. (no prelo).

KAMEl, I.A. \& LitrLe, E.C.S.

1970 - The potential utilization of water hyacinth for horticulture in the Sudan. Pans, 16 (3): 488-496.

KLINGE, $\mathrm{H}$.

1973 - Struktur und Artenreichtum des zentralamazonischen Regenwaldes. Amazoniana, 4 (3): 283-292.

KLOPATEK, J.M

1978 - Nutrient dynamics of freshwater riverine marshes and the role of emergent macrophytes. In: Freshwater wetlands, ecological processes and management potential. Goad, R.E.; Whigham, D.F.; Simpson, R.L. ed. p. 195-216

LITTLE, E.C.S.

1968 - Handbook of utilization of aquatic plants. A compilation of the worlds publications. FAO. Rome, $123 \mathrm{p}$.

LOWE-MCCONNELL, R.H.

1964 - The fishes of the Rupununi savanna district in British Guiana, South America. I. Ecological groupings of fish species and effects of the seasonal cycle on the fish. J. Linn. Soc. (Zool)., 45 (304): 103-144.

Margalef, R.

1968 - Perspectives in ecological theory. Illinois. University of Chicago Press, Chicago, $111 \mathrm{p}$.

MARLIER, G.

1967 - Ecological studies on some lakes of the Amazon valley. Amazoniana, 1: 91-115.

MÜLLER, K.

1951 - Fische und Fischregionen der Fulda. Ber. Limnol. Flusstation Freudenthal, 2: 18-23.

1955 - Quantitative und qualitative Untersuchungen der Fische der Fulda. Hydrobiologia, 7 230244.

NAUManN, E.

1921 - Einige Standpunkte der regionalen Limnologie. Lunds Universitets Arsskrift N. F. avd. 2. $17(8)$.

1931 - Limnologische Terminologie. Handbuch der biologischen Arbeitsmethode, Abt. IX, Teil 8. Urban \& Schwarzenberg, Berlin, $776 \mathrm{p}$.

1932 - Grundzüge der regionalen Limnologie. Die Binnengewasser, 11: 176.
NAumann, E. \& Thienemann, A.

1922 - Vorschlag zur Gründung einer internationalen Vereinigung für theoretische und angewandte Limnologie. Arch. Hydrobiol., 13: 585-605.

Nikonov, M.N. \& SLUKa, V.P.

1964 - The distribution of peatbogs. In: 8th Intern. Congress of Soil Science, Bucharest, 10471055.

Noda, H. \& PAHLEN, A. VON DEN

1978 - Emprego de macrófitas aquáticas ("Matupá") como fonte de matéria orgânica na cultura de feijão-de-asa (Psophocarpus tetragonolobus), em Manaus. Acta Amazonica, 8 (1): 107-109.

ODUM, E.P

1959 - Fundamentals of ecology. London. Toronto. W. B. Saunders Company, 574 p.

PIANKA, E.R.

1970 - On r- and K-selection. Am. Nat., 104: 592597

PRENTKI, R.T.; GUSTAFSON, T.D. \& ADAMS, M.S.

1978 - Nutrient movements in lakeshore marshes In: Freshwater wetlands, ecological processes and management potential. Goad, R.E.; Whingham, D.F.; Simpson, R.L. Ed. p. 169194.

REISS, F.

1976 - Die Benthoszoozönosen zentralamazonischer Várzeaseen und ihre Anpassungen an die jahresperiodischen Wasserstandsschwankungen. Biogeografica, 7: 125-135.

RUTTNER, F

1952 - Fundamentals of limnology. Toronto. University of Toronto Press, $242 \mathrm{p}$.

Rzóska, J.

1978 - On the nature of rivers with case stories of Nile, Zaire, and Amazon. The Hague. W. Junk Publ., 67 p.

SANTOS, G.M.

1979 - Estudo da alimentação, reprodução e aspectos da sistemática de Schizodon fasciatus Agassiz, 1829, Rhytiodus microlepis Kner, 1859 e Rhytiodus argenteofuscus Kner, 1859 do lago Janauacá, AM, Brasil (Osteichthyes, Characoidei, Anostomidae). Tese de Mestrado, INPA/FUA, Manaus, $91 \mathrm{p}$.

SANTOS, U.M.

1973 - Beobachtungen über Wasserbewegungen, chemische Schichtung und Fischwanderungen in Várzea-Seen am mittleren Solimōes (Amazonas). Oecologia, 13: 239-246.

SCHMIDT, G.W.

1973 a - Primary production of phytoplancton in the three types of Amazonian waters. II. The limnology of a tropical flood-plain lake in Central Amazonia (Lago do Castanho). Amazoniana, 4 (2): 139-203. 
$1973 \mathrm{~b}$ - Primary production of phytoplankton in the three types of Amazonian waters. III. Primary productivity of phytoplankton in a tropical ploodplain lake of Central Amazonia, Lago do Castanho, Amazonas, Brazil. Amazoniana, 4 (4): 379-404.

SCHMidr, G.W. \& UHERKovich, G.

1973 - Zur Artenfülle des Phytoplanktons in Amazonien. Amazoniana, 4 (3): 252-253.

Schwabe, G.H. \& Klnnge, $\mathrm{H}$.

1960 - Gewässer und Boden als Forschungsgegenstand. Anales de Edafologia y Agrobiologia, 19 (9-10): 519-568.

SCHWERDTFERGER, F.

1975 - Synökologie. Hamburg, Berlin. Verlag Paul Parey, $451 \mathrm{p}$.

SCHWOERBEL, J.

1971 - Einführung in die Limr.ologie. Stuttgart. Gustav Fischer Verlag, 170 p.

SCUlthorpE, C.D.

1971 - The biology of aquatic vascular plants. London. E. Arnold Ltd., 610 p.

StoLI, H

1954 - Betrochtungen über den Begriff der "Fruchtbarkeit" eines Gebietes anhand der Verhältnisse in Boden und Gewässern Amazoniens. Forsch. Fortschr., 28 (3): 65-72.

1964 - General features of the limnology of Amazonia. Verh. Internat. Verein. Limnol., 15 (2): 1053-1058.

1968 - Hydrochemistry and geology in the Brazilian Amazon region. Amazoniana, 1 (3): 267 277.

1973 - Recent human activities in the Brazilian Amazon region and their ecological effects. In: Meggers, B; Ayensu, E. \& Duckworth,
W.D. (eds.): Tropical forest ecosystems in Africa and South America. Smithsonian Press, Washington, D.C., p. 321-334.

1975 - Tropical rivers as expressions of their terrestrial environments. In: Golley, F. \& Medina, E. (eds.): Tropical ecological systems. New York. Springer Verlag, p. 275-288.

ThiENEMANN, A.

1921 - Biologische Seetypen und die Gründung einer Hydrobiologischen Anstalt am Bodensee. Arch. Hydrobiol., 13: 347-370.

1925 - Die Binnengewässer Mitteleuropas. Eine limnologische Einführung. Die Binnengewässer, 1: $255 \mathrm{p}$.

1932 - Tropische Seen und Seetypenlehre. In: Tropische Binnengewässer 2. Arch. Hydrobiol. Suppl., 9: 205-231.

1933 - Vom Wesen der Limnologie und ihrer Bedeutung für die Kultur der Gegenwart. Verh. Internat. Verein. Limnol., 6: 21-27.

TISCHLER, W.

1955 - Synökologie der Landtiere. Fischer, Stuttgart.

ULE, W.

1925 - Physiographie des Süsswassers. In: Enzyklopädie der Erdkunde. Leipzig. Wien.

W'ELCOMME, R.L.

1979 - Fisheries ecology of floodplain rivers. The Chancer Press Ltd., Bungay, Suffolk, (LongLondon, New York), 317 p.

WETZEL, R.G.

1975 - Limnology. Philadelphia. W.B. Saunders Company, $743 \mathrm{p}$.

(Aceito para publicação em $5 / 12 / 80$. Prioridade autorizada) 